\title{
Olanzapine Sensitization and Clozapine Tolerance: From Adolescence to Adulthood in the Conditioned Avoidance Response Model
}

\author{
Jing Qiao ${ }^{1,2}$, Hong $\mathrm{Li}^{1,3}$ and Ming $\mathrm{Li}^{*, 2}$ \\ 'Key Laboratory of Cognition and Personality (Southwest University), Ministry of Education, Institute of Psychology, Southwest University, \\ Chongqing, China; ${ }^{2}$ Department of Psychology, University of Nebraska-Lincoln, Lincoln, NE, USA
}

\begin{abstract}
Disruption of conditioned avoidance response (CAR) in rodents is one trademark feature of many antipsychotic drugs. In adult rats, repeated olanzapine (OLZ) treatment causes an enhanced disruption of avoidance response (sensitization), whereas repeated clozapine (CLZ) treatment causes a decreased disruption (tolerance). The present study addressed (I) whether OLZ sensitization and CLZ tolerance can be induced in adolescent rats, and (2) the extent to which OLZ sensitization and CLZ tolerance induced in adolescence persists into adulthood. Male adolescent Sprague-Dawley rats (approximate postnatal days ( $\sim P) 43-47$ ) were first treated with $O L Z$ ( 1.0 or $2.0 \mathrm{mg} / \mathrm{kg}$, subcutaneously (sc)) or CLZ (I0 or $20 \mathrm{mg} / \mathrm{kg}, \mathrm{sc}$ ) daily for 5 consecutive days in the CAR model. They were then tested for the expression of $O L Z$ sensitization or $C L Z$ tolerance either in adolescence ( $\sim P 50)$ or after they matured into adults ( $\sim P 76$ and 92) in a challenge test during which all rats were injected with either a lower dose of $O L Z(0.5 \mathrm{mg} / \mathrm{kg})$ or CLZ $(5.0 \mathrm{mg} / \mathrm{kg})$. When tested in adolescence, rats previously treated with $O L Z$ showed a stronger inhibition of CAR than those previously treated with vehicle (ie, sensitization). In contrast, rats previously treated with CLZ showed a weaker inhibition of CAR than those previously treated with vehicle (ie, tolerance). When tested in adulthood, the OLZ sensitization was still detectable at both time points ( $\sim$ P 76 and 92 ), whereas the $\mathrm{CLZ}$ tolerance was only detectable on $\sim P 76$, and only manifested in the intertrial crossing. Performance in the prepulse inhibition and fear-induced $22 \mathrm{kHz}$ ultrasonic vocalizations in adulthood were not altered by adolescence drug treatment. Collectively, these findings suggest that atypical antipsychotic treatment during adolescence can induce a long-term specific alteration in antipsychotic effect that persists into adulthood despite the brain maturation. As antipsychotic drugs are being increasingly used in children and adolescents in the past two decades, findings from this study are important for understanding the impacts of adolescent antipsychotic treatment on the brain and behavioral developments. This work also has implications for clinical practice involving adolescence antipsychotic treatments in terms of drug choice, drug dose, and schedule.

Neuropsychopharmacology (2013) 38, 513-524; doi:I0.1038/npp.2012.213; published online 7 November 2012
\end{abstract}

Keywords: adolescence antipsychotic treatment; conditioned avoidance response; prepulse inhibition; $22 \mathrm{kHz}$ ultrasonic vocalization; sensitization; tolerance

\section{INTRODUCTION}

Antipsychotic drugs are the primary medications used to treat psychosis. Like many other psychoactive drugs, repeated administration of these drugs often induces various clinically relevant sensitization and tolerance effects in many behavioral domains (Emmett-Oglesby and Goudie, 1989). The specific long-term patterns (ie, sensitization or tolerance) of antipsychotic treatment appear to depend on several factors, including classes of drugs, treatment

*Correspondence: Professor Ming Li, Department of Psychology, University of Nebraska-Lincoln, 238 Burnett Hall, Lincoln, NE 685880308, USA, Tel: + I 402-472-3I44, Fax: 402-4724637.

E-mail:mli2@unl.edu

${ }^{3}$ Current address: Research Center for Psychological Development and Education, Liaoning Normal University, Liaoning I 16029, China

Received 24 July 2012; revised 27 September 2012; accepted 27 September 2012 schedule, drug dose, and behavioral testing conditions (Barnes et al, 1990; Remington and Kapur, 2010).

In recent years, we have used the conditioned avoidance response (CAR) and phencyclidine (PCP)-induced hyperlocomotion, two models with high predictive validity for antipsychotic efficacy (Gleason and Shannon, 1997; Natesan et al, 2005; Wadenberg, 2010), to examine the long-term treatment effects of antipsychotic drugs. We employed a behavioral paradigm similar to those used for the study of psychomotor sensitization (Stewart and Badiani, 1993; Robinson et al, 1998). First, rats are repeatedly treated with an antipsychotic drug or vehicle for a certain number of days (eg, 5 or 7 days), and their avoidance responses and PCP-induced hyperlocomotion are recorded. This period is termed the induction phase. A few days later, all rats are given a challenge dose of the drug to assess the expression of antipsychotic sensitization or tolerance (termed the expression phase). In the induction phase, antipsychotic 
sensitization or tolerance is observed if the avoidancedisruptive effect or the inhibitory effect on PCP-induced hyperlocomotion of the drug increases or decreases in magnitude throughout the treatment period. In the expression phase, sensitization or tolerance is shown if the drugtreated animals exhibit a stronger (ie, less avoidance responses or lower PCP-induced hyperlocomotion) or weaker response (ie, more avoidance responses or higher PCP-induced hyperlocomotion) than the vehicle-treated ones (Li et al, 2010).

Using such a paradigm, we show that repeated treatment of haloperidol and olanzapine (OLZ) induce a sensitization effect in both the induction and expression phases (Li et al, 2009b; Li et al, 2009a; Sun et al, 2009; $\mathrm{Li}$ et al, 2010; Mead and Li, 2010; Zhao et al, 2012). In contrast, repeated treatment of clozapine (CLZ) does not cause an apparent sensitization or tolerance during the induction phase (Sun et al, 2009; Li et al, 2010). But in the expression phase when all rats are injected with a low dose of CLZ, rats previously treated with CLZ exhibit a tolerance effect, as they often make significantly more avoidance responses and exhibit higher PCP-induced hyperlocomotion than those that are treated with CLZ for the first time (Li et al, 2010).

So far, all the antipsychotic sensitization and tolerance studies have been done in adult rats. One interesting and important question arises: if an antipsychotic drug is administered to adolescent rats (35-60 days old; Andersen et al, 2000) for a certain number of days, after they become adults, will they still show an enhanced (sensitization) or decreased (tolerance) response to the drug? The answer to this question will not only increase our understanding of the behavioral mechanisms involved in antipsychotic treatment, but also allow us to study the long-term impacts of such exposure to antipsychotic drugs on brain development and behavioral functions. The present study reports our investigation of the OLZ sensitization and CLZ tolerance in the CAR model across the adolescence and adulthood periods. Similar results have been found in the PCP-induced hyperlocomotion model (unpublished observations). As sensitization and tolerance often develop to a particular effect of a drug, but not to a drug itself, in order to assess the behavioral specificity of OLZ sensitization and CLZ tolerance, we also examined their effects on $22 \mathrm{kHz}$ ultrasonic vocalization (USV, a measure of fear/anxiety; Mead et al, 2008; Sun et al, 2010) and on intertrial crossing in the CAR task (a putative measure of motor function/ sedation). In addition, we examined the prepulse inhibition (PPI) of acoustic startle response of the rats periodically throughout their developmental period (approximate postnatal days, $(\sim \mathrm{P}) 43-47)$ as a way to assess how adolescence antipsychotic treatment affects the brain and behavioral functions and development of adolescent rats. PPI refers to the phenomenon of a reduction in the startle magnitude when the startling stimulus is preceded by a lowintensity prepulse. It measures the sensorimotor gating ability, a basic pre-attentive cognitive function, which is impaired in patients with schizophrenia and in animals acutely treated with dopamine agonists and NMDA antagonists (Geyer and Braff, 1987; Swerdlow et al, 2008). This task was chosen also because adolescence antipsychotic treatment has been found to cause an impairment of PPI performance under certain conditions (Meyer et al, 2010; Llorente-Berzal et al, 2012).

\section{MATERIALS AND METHODS}

\section{Animals}

Male Sprague-Dawley adolescent rats from Charles River (Portage, MI; P 22-26, averaged age was assumed at P 24, 51-75 $\mathrm{g}$ on delivery date) were used. They were housed two per cage, in $48.3 \times 26.7 \times 20.3 \mathrm{~cm}$ transparent polycarbonate cages under $12 \mathrm{~h}$ light/dark conditions (light on between 0630 and $1830 \mathrm{~h}$ ). Room temperature was maintained at $22 \pm 1{ }^{\circ} \mathrm{C}$ with a relative humidity of $45-60 \%$. Food and water was available ad libitum. Animals were allowed at least 5 days of habituation to the animal facility before being used in experiments ( $\sim \mathrm{P} 31)$. All procedures were approved by the Institutional Animal Care and Use Committee at the University of Nebraska-Lincoln.

\section{Drugs and Choice of Doses}

Both OLZ and CLZ (gifts from the NIMH drug supply program) were dissolved in distilled sterile water with 1.0$1.5 \%$ glacial acetic acid. They were administrated subcutaneously (sc) at $1 \mathrm{ml} / \mathrm{kg}$. Two doses of OLZ (1.0 and $2.0 \mathrm{mg} /$ $\mathrm{kg}$ ) and CLZ (10 and $20 \mathrm{mg} / \mathrm{kg}$ ) were tested. These doses of OLZ and CLZ produce a reliable and comparable disruption on avoidance responding ( $\mathrm{Li}$ et al, 2004; Li et al, 2007; Li et al, 2009b; Li et al, 2010; Mead and Li, 2010; Zhang and Li, 2012). On the basis of data from the striatal dopamine $D_{2}$ receptor occupancy study in rats (Kapur et al, 2003), we estimated that both drugs at these doses would give rise to a $40-80 \%$ striatal $\mathrm{D}_{2}$ occupancy, which is comparable to values observed in schizophrenic patients (Kapur et al, 1999).

\section{Two-Way Avoidance Conditioning Apparatus}

Eight identical two-way shuttle boxes custom-designed and manufactured by Med Associates (St Albans, VT) were used. Each box was housed in a ventilated, sound-insulated isolation cubicle $(96.52 \mathrm{~cm} \mathrm{~W} \times 35.56 \mathrm{~cm} \mathrm{D} \times 63.5 \mathrm{~cm} \mathrm{H})$. Each box was $64 \mathrm{~cm}$ long, $30 \mathrm{~cm}$ high (from grid floor), and $24 \mathrm{~cm}$ wide, and was divided into two equal-sized compartments by a partition with an arch style doorway $(15 \mathrm{~cm}$ high $\times 9 \mathrm{~cm}$ wide at base). A barrier $(4 \mathrm{~cm}$ high) was placed between the two compartments, so the rats had to jump from one compartment to the other. The grid floor consisted of 40 stainless-steel rods with a diameter of $0.48 \mathrm{~cm}$, spaced $1.6 \mathrm{~cm}$ apart center to center, through which a scrambled footshock (unconditioned stimulus, US, $0.8 \mathrm{~mA}$, maximum duration: $5 \mathrm{~s}$ ) was delivered by a constant current shock generator (Model ENV-410B) and scrambler (Model ENV-412). The rat location and crossings between compartments were monitored by a set of 16 photobeams (ENV-256-8P) affixed at the bottom of the box $(3.5 \mathrm{~cm}$ above the grid floor). Illumination was provided by two houselights mounted at the top of each compartment. The conditioned stimulus (CS) (ie, $76 \mathrm{~dB}$ white noise) was produced by a speaker (ENV 224 AMX) mounted on the ceiling of the cubicle, centered above the shuttle box. Background noise (approximately $74 \mathrm{~dB}$ ) was provided by a 
ventilation fan affixed at the top corner of each isolation cubicle. All training and testing procedures were controlled by Med Associates programs running on a computer.

In each CAR box, an USV microphone ( $P$ 48/Emkay Microphone, Avisoft Bioacoustics, Berlin, Germany) was mounted on the ceiling of the two-compartment chamber. The microphone was connected via an E-MU 0404 USB Audio device to a computer. Acoustic data were displayed in real time by the Avisoft RECORDER, a multi-channel triggering hard-disk recording software (version 3.4; Avisoft Bioacoustics), and were recorded at a sampling rate of $192 \mathrm{kHz}$ in 16 bit format and analyzed by Avisoft SASLab Pro (version 4.51; Avisoft Bioacoustics).

\section{PPI of Acoustic Startle Reflex Apparatus}

The PPI test was performed using six Startle Monitor Systems (Kinder Scientific, Julian, CA). Each system, controlled by a PC, was housed in a compact sound attenuation cabinet $(36 \mathrm{~cm}$ wide $\times 28 \mathrm{~cm}$ deep $\times 50 \mathrm{~cm}$ high). A speaker (diameter: $11 \mathrm{~cm}$ ) mounted on the cabinet's ceiling was used to generate acoustic stimuli $(70-120 \mathrm{~dB})$. The startle response was measured by a piezoelectric sensing platform on the floor, which was calibrated daily. During testing, rats were placed in a rectangular box made of transparent Plexiglas $(19 \mathrm{~cm}$ wide $\times 9.8 \mathrm{~cm}$ deep $\times 14.6 \mathrm{high})$ with an adjustable ceiling positioned atop the box, providing only limited restraint while prohibiting ambulation.

\section{Experiment 1: OLZ Sensitization Induced in Adolescence and Assessed in Adolescence}

This experiment examined whether repeated OLZ treatment could induce a sensitization effect in adolescent rats in the CAR model as previously found in adult rats (Li et al, 2010; Mead and Li, 2010; Li et al, 2012; Swalve and Li, 2012; Zhang and $\mathrm{Li}, 2012$ ). It consisted of three phases: avoidance training, induction of OLZ sensitization, and sensitization assessment.

Avoidance training. Twenty-nine rats $(\sim \mathrm{P} 31)$ were first habituated to the CAR boxes for 2 days $(30 \mathrm{~min} /$ day) and then trained for conditioned avoidance responding for 10 consecutive days/sessions. Each session consisted of 30 trials. Every trial started by presenting a white noise (CS) for $10 \mathrm{~s}$, followed by a continuous scrambled footshock $(0.8 \mathrm{~mA}$, US, maximum duration $=5 \mathrm{~s}$ ) on the grid floor. If a subject moved from one compartment into the other within the $10 \mathrm{~s}$ of CS presentation, it avoided the shock, and this shuttling response was recorded as 'avoidance'. If the rat remained in the same compartment for more than $10 \mathrm{~s}$ and made a crossing upon receiving the footshock, this response was considered as 'escape'. If the rat did not respond during the entire $5 \mathrm{~s}$ presentation of the shock, the trial was terminated and 'escape failure' was recorded. The total number of avoidance responses was recorded for each session. Intertrial intervals varied randomly between 30 and $60 \mathrm{~s}$.

Induction of OLZ sensitization. At the end of the training session ( $\sim \mathrm{P} 43)$, rats were first matched based on avoidance performance on the last training day (ie, predrug) to create blocks of rats ( $n=3$ rats/block) that were approximately equal in performance. Within each block, they were then randomly assigned to one of three groups: vehicle (sterile water, $n=10$ ), OLZ $1.0 \mathrm{mg} / \mathrm{kg}$ (OLZ $1.0, n=10$ ), and OLZ $2.0 \mathrm{mg} / \mathrm{kg}$ (OLZ 2.0, $n=9$ ), and tested daily for avoidance response for 5 consecutive days. The CS-only (no shock, 30 trials/daily session) condition was used to eliminate any relearning effect caused by the presence of the US. During each drug test, rats were first injected with OLZ or sterile water. One hour later, they were placed in the CAR boxes and tested. USVs at the $22 \mathrm{kHz}$ range $(20-32 \mathrm{kHz})$ were also recorded for the first $10 \mathrm{~min}$ of testing using Avisoft Recorder software (Version 3.4). Settings included sampling rate at $192 \mathrm{kHz}$, format 16 bit. For acoustical analysis, recordings were transferred to Avisoft SASLab Pro (Version 4.51) and a fast Fourier transformation was conducted. Spectrograms were generated with a fast Fourier transformation length of 256 points and a time window overlap of $50 \%$ (100\% Frame, FlatTop window). The spectrogram was produced at a frequency resolution of $750 \mathrm{~Hz}$ and a time resolution of $0.6667 \mathrm{~ms}$. Call detection was provided by an automatic single threshold-based algorithm (threshold: $-20 \mathrm{~dB}$ ) and a hold-time mechanism (hold time: $0.02 \mathrm{~s}$ ). In addition, the number of intertrial crossings (crossings during the intertrial intervals) in each session was also recorded.

Sensitization assessment. One day after the last drug test day, all rats were retrained drug-free for 1 day under the CSonly (no shock; $\sim$ P 48) condition and 1 day under the CSUS condition $(\sim P 49)$ to ensure all groups had a comparable level of avoidance responding before the sensitization assessment. OLZ sensitization was assessed 1 day later $(\sim \mathrm{P} 50)$ when all rats were injected with a challenge dose of OLZ $0.5 \mathrm{mg} / \mathrm{kg}$ and tested for avoidance performance, $22 \mathrm{kHz}$ USV, and intertrial crossings in the CS-only condition (30 trials) $1 \mathrm{~h}$ later. This procedure of using a lower challenge dose of OLZ has been successfully used in our previous studies (Li et al, 2010; Li et al, 2012; Sparkman and Li, 2012; Swalve and Li, 2012; Zhang and Li, 2012). It also avoided the floor effect (ie, a high dose may cause a maximal avoidance disruption, leaving no room to show a sensitization or tolerance effect).

\section{Experiment 2: CLZ Tolerance Induced in Adolescence and Assessed in Adolescence}

This experiment examined whether repeated CLZ treatment could induce a tolerance effect in adolescent rats in the CAR model as previously found in adult rats ( $\mathrm{Li}$ et al, 2010; Li et al, 2012). The basic procedure was identical to that of Experiment 1, with the exceptions that 27 adolescent rats were used and 2 doses of CLZ ( 10 and $20 \mathrm{mg} / \mathrm{kg}$, sc) were administered during the adolescence period. CLZ $5.0 \mathrm{mg} / \mathrm{kg}$ was used as a challenge dose during the tolerance assessment test $(\sim \mathrm{P} 50)$. The three groups were: vehicle (sterile water, $n=9$ ), CLZ $10 \mathrm{mg} / \mathrm{kg}$ (CLZ 10, $n=9$ ), and CLZ $20 \mathrm{mg} / \mathrm{kg}$ (CLZ 20, $n=9$ ).

\section{Experiment 3: OLZ Sensitization Induced in Adolescence and Assessed in Adulthood}

This experiment examined whether the sensitization effect induced by repeated OLZ treatment to adolescent rats in the CAR model persisted throughout the adolescence period and 
Table I Timeline of Events Occurred in Experiment 3 and 4

\begin{tabular}{|c|c|c|}
\hline $\begin{array}{l}\text { Days of } \\
\text { study }\end{array}$ & $\begin{array}{l}\text { Approximate } \\
\text { age (years) }\end{array}$ & Manipulation \\
\hline $1-2$ & PND $31-32$ & Habituation to CAR boxes ( $30 \mathrm{~min} /$ day) \\
\hline $3-12$ & PND 33-42 & 10 Days of CAR training (CS-US) \\
\hline $13-17$ & PND 43-47 & 5 Days of drug testing (CS-only) \\
\hline 18 & PND 48 & Ist PPI test \\
\hline $19-36$ & PND 49-66 & Rest \\
\hline 37 & PND 67 & 2nd PPI test \\
\hline 38 & PND 68 & Habituation to CAR boxes ( $30 \mathrm{~min} /$ day) \\
\hline $39-45$ & PND 69-75 & 7 days of CAR retraining (CS-US) \\
\hline 46 & PND 76 & $\begin{array}{l}\mathrm{I}^{\text {st }} \text { drug challenge test (CS-only): OLZ } \\
0.50 \mathrm{mg} / \mathrm{kg}, \text { CLZ } 5.0 \mathrm{mg} / \mathrm{kg}\end{array}$ \\
\hline 47 & PND 77 & $3^{\text {rd }} \mathrm{PPI}$ test \\
\hline $48-59$ & PND 78-89 & Rest \\
\hline 60 & PND 90 & $1^{\text {st }}$ retraining (CS-only) \\
\hline 61 & PND 91 & 2nd retraining (CS-US) \\
\hline 62 & PND 92 & $\begin{array}{l}\text { 2nd drug challenge test (CS-only): OLZ } \\
0.50 \mathrm{mg} / \mathrm{kg}, \mathrm{CLZ} 5.0 \mathrm{mg} / \mathrm{kg}\end{array}$ \\
\hline
\end{tabular}

The bold text highlight the critical steps of the experiments.

into adulthood. It consisted of the following three components: avoidance training/induction of OLZ sensitization during adolescence, sensitization assessment during adulthood, and PPI assessment. Table 1 details the timeline of events.

Avoidance training/induction of $O L Z$ sensitization during adolescence. The basic procedure was identical to that of Experiment 1 . Forty adolescent rats ( $\sim$ P 31) were used, of which 32 were trained for conditioned avoidance responding for 10 consecutive days/sessions. The remaining eight rats served as a control group (termed the CS-only group) for the training effect. They were subjected to the same CAR procedure, with the only exception that no shock was ever given, thus they were not trained for CAR.

At the end of the training session ( $\sim \mathrm{P} 43)$, the 32 trained rats were matched and randomly assigned to one of three groups: vehicle (sterile water, $n=11)$, OLZ $1.0(n=10)$, and OLZ $2.0(n=11)$, and tested daily for avoidance response for 5 consecutive days. The CS-only rats $(n=8)$ were also tested under the same condition under vehicle.

Sensitization assessment in adulthood on $P 76$ and 92. Rats remained in their home cages until $\sim \mathrm{P} 68$, when all rats were returned to the CAR boxes for one habituation session, followed by 7 days of CAR training/retraining to ensure all groups had a comparable level of avoidance responding before the sensitization assessment. The CSonly group was also trained for CAR. The OLZ sensitization was assessed 1 day after the seventh training session $(\sim \mathrm{P}$ 76), with all rats being injected with a challenge dose of OLZ $0.5 \mathrm{mg} / \mathrm{kg}$. On P 90 and 91, all rats were given two CAR retraining sessions (the first under the CS-only and the second under the CS-US condition) to bring their avoidance back to the predrug level. The second OLZ sensitization test was conducted 1 day later under the same challenge dose of OLZ $(0.5 \mathrm{mg} / \mathrm{kg})$.
PPI assessment. A total of three PPI tests were conducted throughout the developmental period. The first one was done during the late adolescence period ( P 48, 1 day after the 5 drug test days), the second one during the early adulthood period ( $\sim \mathrm{P} 67,2$ days before the CAR retraining). The third one ( $\sim \mathrm{P} 77$ ) was conducted 1 day after the sensitization test in the CAR.

The PPI test procedure was adapted from Culm and Hammer (2004). Each session lasted approximately $18 \mathrm{~min}$ and began with a 5 -min period of $70 \mathrm{~dB}$ background noise (which continued throughout the duration of the session) followed by four different trial types: PULSE ALONE trials and three types of PREPULSE + PULSE trials, which consisted of a $20 \mathrm{~ms} \mathrm{73,76}$, or $82 \mathrm{~dB}$ prepulse $(3,6$, and $12 \mathrm{~dB}$ above background) later followed by $100 \mathrm{~ms}$ of $120 \mathrm{~dB}$ pulse. Each session was divided into four blocks. Blocks 1 and 4 were identical, each consisting of four PULSE ALONE trials. Blocks 2 and 3 were also identical and each consisted of eight PULSE ALONE trials and five of each PREPULSE + PULSE trial type. A total of 54 trials were presented during each test session. Trials within each block were presented in a pseudorandom order and were separated by a variable intertrial interval averaging $15 \mathrm{~s}$ (ranging from 9 to $21 \mathrm{~s}$ ). Startle magnitude was defined as the maximum force (measured in Newtons) applied by the rat to the startle apparatus recorded over a period of $100 \mathrm{~ms}$ beginning at the onset of the pulse stimulus. Between each stimulus trial, $100 \mathrm{~ms}$ of activity was recorded when no stimulus was present. These trials were called NOSTIM trials and were not included in the calculation of intertrial intervals. Responses recorded during NOSTIM trials are considered a measure of gross motor activity within the PPI boxes. Startle responses from testing blocks 2 and 3 were used to calculate \%PPI for each acoustic prepulse trial type:

$\% \mathrm{PPI}=100-\left[\left(\frac{\text { Average startle response to PREPULSE }+ \text { PULSE trials }}{\text { Average startle response to PULSE ALONE trials }}\right) \times 100\right]$

\section{Experiment 4: CLZ Tolerance Induced in Adolescence and Assessed in Adulthood}

This experiment examined whether the tolerance effect induced by repeated CLZ treatment to adolescent rats in the CAR model persisted throughout the adolescence period and into adulthood. The basic procedure was identical to that of Experiment 3, with the exceptions that two doses of CLZ (10 and $20 \mathrm{mg} / \mathrm{kg}$, sc) instead of OLZ were administered during the adolescence period, and the challenge dose of CLZ $(5.0 \mathrm{mg} / \mathrm{kg})$ was used during the tolerance assessment tests (see Table 1). The four groups were: vehicle (sterile water, $n=11)$, CLZ $10(n=10)$, CLZ $20(n=11)$, and CS-only (sterile water, $n=8$ ).

\section{Statistical Analysis}

All data were expressed as mean + SEM. Avoidance data from the five drug test sessions were analyzed using a factorial repeated measures analysis of variance (ANOVA) with the between-subjects factor being drug group and the within-subjects factor being test day, followed by post hoc LSD tests. Data from the retraining/predrug days and from the challenge tests were analyzed by a one-way ANOVA 

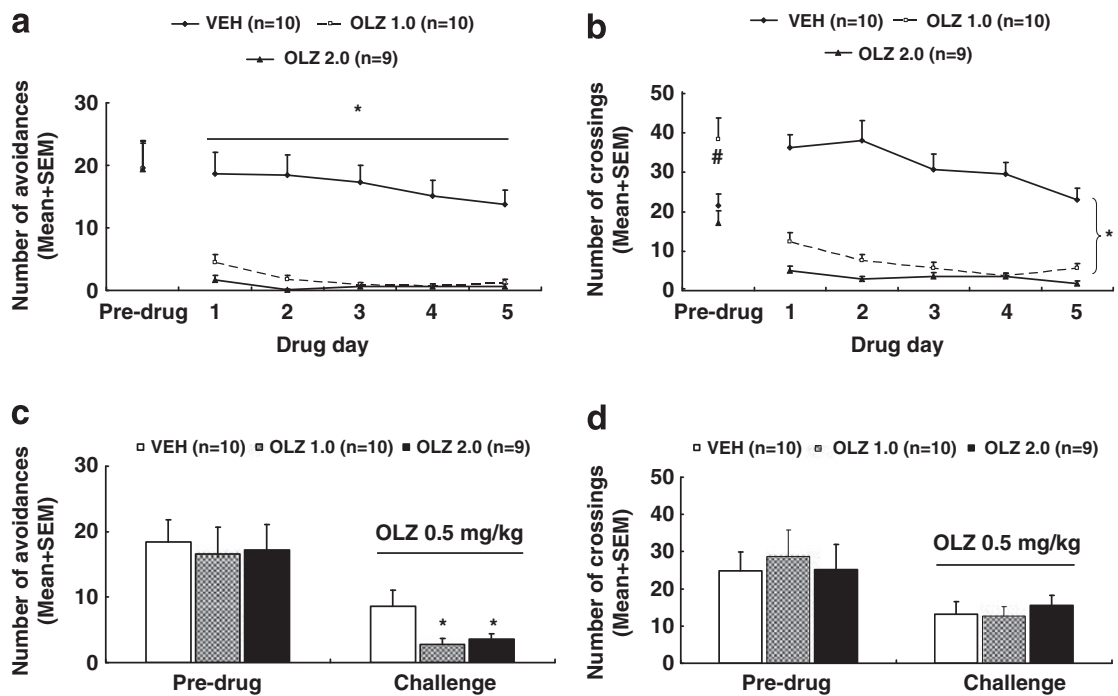

Figure I Olanzapine $(O L Z)$ sensitization induced in adolescence and assessed in adolescence. Number of avoidance responses (a) and intertrial crossing (b) made by the rats from the $O L Z(I .0 \mathrm{mg} / \mathrm{kg}), O L Z(2.0 \mathrm{mg} / \mathrm{kg})$, and vehicle $(\mathrm{VEH})$ groups on the last training (predrug) day and throughout the five drug test days are expressed as mean + SEM. The same measures on the second retraining (predrug) day and the OLZ sensitization assessment day are also expressed as mean + SEM and depicted in c and d, respectively. ${ }^{*} p<0.05$ relative to the VEH group; ${ }^{\#} p<0.05$ relative to the OLZ 2.0 and VEH groups.

followed by post hoc LSD tests (for more than three groups). The \%PPI data were presented separately for three prepulse intensities (eg, 73, 76, and $82 \mathrm{~dB}$ ) and were analyzed using repeated measures ANOVAs with drug treatment group as a between-subjects factor and prepulse level as a withinsubjects factor. For all analyses, $p<0.05$ was considered statistically significant.

\section{RESULTS}

\section{Experiment 1: OLZ Sensitization Induced in Adolescence and Assessed in Adolescence}

Avoidance training and induction of OLZ sensitization. Avoidance response: Figure 1a shows the number of avoidance responses on the last training (predrug) day and five drug test days. There was no group difference on the last training day. Throughout the drug test phase, OLZ treatment disrupted avoidance response persistently. Repeated measures ANOVA revealed a main effect of group, $\mathrm{F}(2,26)=31.437, \quad p<0.001$ and day, $\mathrm{F}(4,104)=5.105$, $p=0.001$, but no significant group $\times$ day interaction. Post hoc LSD tests revealed that the two OLZ groups differed significantly from the $\mathrm{VEH}$ group, all $p<0.001$, although they did not differ significantly from each other.

$22 \mathrm{kHz}$ USV: OLZ also decreased the number of $22 \mathrm{kHz}$ USV (Supplementary Table S1). On the predrug day, there was no significant group difference. During the drug test days, the two OLZ groups had fewer $22 \mathrm{kHz}$ USVs in comparison with the VEH group, especially on the first test day. Repeated measures ANOVA revealed a main effect of day, $\mathrm{F}(4,104)=3.860, p=0.006$ and a significant group $\times$ day interaction, $F(8,104)=2.982, p=0.005$. One-way ANOVAs on each test day revealed that only on the first test day did the OLZ 2.0 group show significantly fewer USV counts than the VEH group, $p=0.037$.

Intertrial crossing: Unexpectedly, the OLZ 1.0 group had more intertrial crossings on the last training day than the other two groups, $p<0.007$ (Figure 1b). Throughout the drug test phase, OLZ treatment progressively suppressed the intertrial crossing. Repeated measures ANOVA revealed a main effect of group, $F(2,26)=57.450, p<0.001$, a main effect of day, $F(4,104)=12.528, p<0.001$, and a significant group $\times$ day interaction, $F(8,104)=4.239, p<0.001$. Post hoc LSD tests revealed that the two OLZ groups differed significantly from the VEH group, all $p<0.001$, although they did not differ significantly from each other.

\section{OLZ sensitization assessment.}

Avoidance response: Figure 1c shows the number of avoidance responses on the second retraining (predrug) day and the OLZ sensitization test day ( $\sim$ P 50). Before the OLZ challenge, there was no significant group difference. On the challenge day when all rats were injected with OLZ $0.5 \mathrm{mg} / \mathrm{kg}$, the two OLZ groups made fewer avoidance responses than the VEH group. One-way ANOVA confirmed this observation, as there was a significant effect of group, $F(2,26)=3.749$, $p=0.037$. Post hoc LSD tests showed that the OLZ 2.0 and OLZ 1.0 groups were significantly different from the VEH group, $p=0.042$ and 0.018 , respectively.

$22 \mathrm{kHz}$ USV and intertrial crossing: No significant group difference was detected on the number of $22 \mathrm{kHz}$ USVs on the predrug day and on the challenge day (Supplementary Table S1). Similarly, no significant group difference was detected on the intertrial crossing on the predrug day and on the challenge day (Figure 1d).

Collectively, the above results indicate that repeated OLZ treatment induced a robust sensitization effect during adolescence. This effect was dose-dependent and specific to avoidance response, but not to $22 \mathrm{kHz}$ USVs and intertrial crossing.

\section{Experiment 2: CLZ Tolerance Induced in Adolescence} and Assessed in Adolescence

Avoidance training and induction of CLZ tolerance. Avoidance response: Figure $2 \mathrm{a}$ shows the number of avoidance responses on the last training day (predrug) 

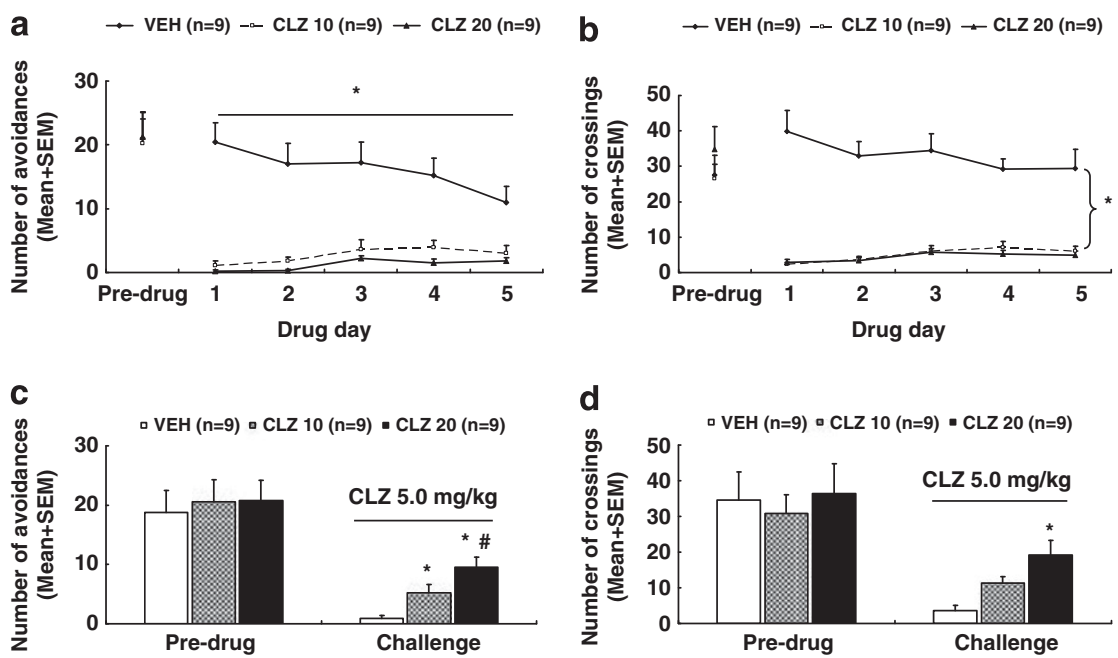

Figure 2 Clozapine (CLZ) tolerance induced in adolescence and assessed in adolescence. Number of avoidance responses (a) and intertrial crossing (b) made by the rats from the CLZ (I $0.0 \mathrm{mg} / \mathrm{kg}), C L Z(20.0 \mathrm{mg} / \mathrm{kg})$, and vehicle $(V E H)$ groups on the last training (predrug) day and throughout the five drug test days are expressed as mean + SEM. The same measures on the second retraining (predrug) day and the CLZ tolerance assessment day are also expressed as mean + SEM and depicted in $\mathrm{c}$ and $\mathrm{d}$, respectively. ${ }^{*} p<0.05$ relative to the VEH group; ${ }^{*} p<0.05$ relative to the CLZ I0 group.

and five drug test days. There was no group difference on the last training day. Throughout the drug test days, CLZ treatment severely disrupted avoidance response. Repeated measures ANOVA revealed a main effect of group, $F(2,24)$ $=26.498, p<0.001$ and day, $F(4,96)=2.772, p=0.031$, and a significant group $\times$ day interaction, $F(8,96)=6.016$, $p<0.001$. Post hoc LSD tests revealed that the two CLZ groups differed significantly from the VEH group, all $p<0.001$, although they did not differ significantly from each other.

$22 \mathrm{kHz}$ USV: On the last training day (Supplementary Table S2), there was no significant group difference. During the drug test period, repeated measures ANOVA also failed to find a main effect of group, day, nor their interaction. Post hoc LSD tests also failed to find any group difference, $p>0.056$.

Intertrial crossing: There was no significant group difference on the last training day (Figure 2b). Throughout the drug test phase, CLZ treatment suppressed the intertrial crossing. Repeated measures ANOVA revealed a main effect of group, $F(2,24)=44.520, p<0.001$ and a significant group $\times$ day interaction, $F(8,96)=4.170, p<0.001$, but no main effect of day. Post hoc LSD tests revealed that the two CLZ groups differed significantly from the VEH group, all $p<0.001$, although they did not differ significantly from each other.

\section{CLZ tolerance assessment.}

Avoidance response: Figure $2 \mathrm{c}$ shows the number of avoidance responses on the second retraining (predrug) day and the CLZ tolerance test day $(\sim \mathrm{P} 50)$. Before the CLZ challenge, there was no significant group difference. On the challenge day when all rats were injected with CLZ $5.0 \mathrm{mg} / \mathrm{kg}$, the two CLZ groups made more avoidance responses than the VEH group. One-way ANOVA revealed a significant effect of group, $F(2,24)=11.436, p<0.001$. Post hoc LSD tests showed that the CLZ 10 and CLZ 20 groups were significantly different from the VEH group, $p=0.025$ and $p<0.001$, respectively, and the CLZ 20 group was also significantly different from the CLZ 10 group, $p=0.025$.
$22 \mathrm{kHz}$ USV and intertrial crossing: The number of $22 \mathrm{kHz}$ USV was not significantly different among groups on the predrug day and on the challenge day (Supplementary Table S2). Similarly, no significant group difference was detected on the intertrial crossing on the predrug day (Figure $2 \mathrm{~d}$ ). However, there was a significant group difference on the challenge test, $F(2,24)=8.401, p=0.002$. Post hoc tests showed that the CLZ 20 group made more crossings than the VEH group, $p<0.001$, whereas the CLZ 10 group was only marginally different from the VEH group, $p=0.053$, and marginally different from the CLZ 20 group, $p=0.050$.

Overall, these results indicate that repeated CLZ treatment induced a robust tolerance effect during adolescence. This effect was dose-dependent and specific to avoidance response, but not to $22 \mathrm{kHz}$ USV. It was also manifested in the intertrial crossings.

\section{Experiment 3: OLZ Sensitization Induced in Adolescence and Assessed in Adulthood}

Avoidance response during adolescence: Figure 3 a shows the number of avoidance responses made by the rats in the four groups on the last adolescence training day and throughout the five drug test days. At the end of the training phase, rats trained in the CAR had a significant higher level of avoidance responding than the CS-only rats (the average was $13.22+2.16$ vs $3.13+1.03$, respectively, $t_{38}=-4.227$, $p<0.001)$. During the drug test days, the two OLZ groups and the CS-only group had fewer avoidance responses, whereas the VEH group maintained a high level of avoidance responding. Repeated measures ANOVA revealed a main effect of group, $F(3,36)=13.673, p<0.001$; day, $F(4,144)=2.592, p=0.039$, and a significant group $\times$ day interaction, $F(12,144)=3.506, p<0.001$. Post hoc LSD tests revealed that the two OLZ groups were significantly different from the VEH group, all $p<0.001$, but not significantly different from the CS-only group. The CS-only group also differed significantly from the VEH group, $p=0.001$. 

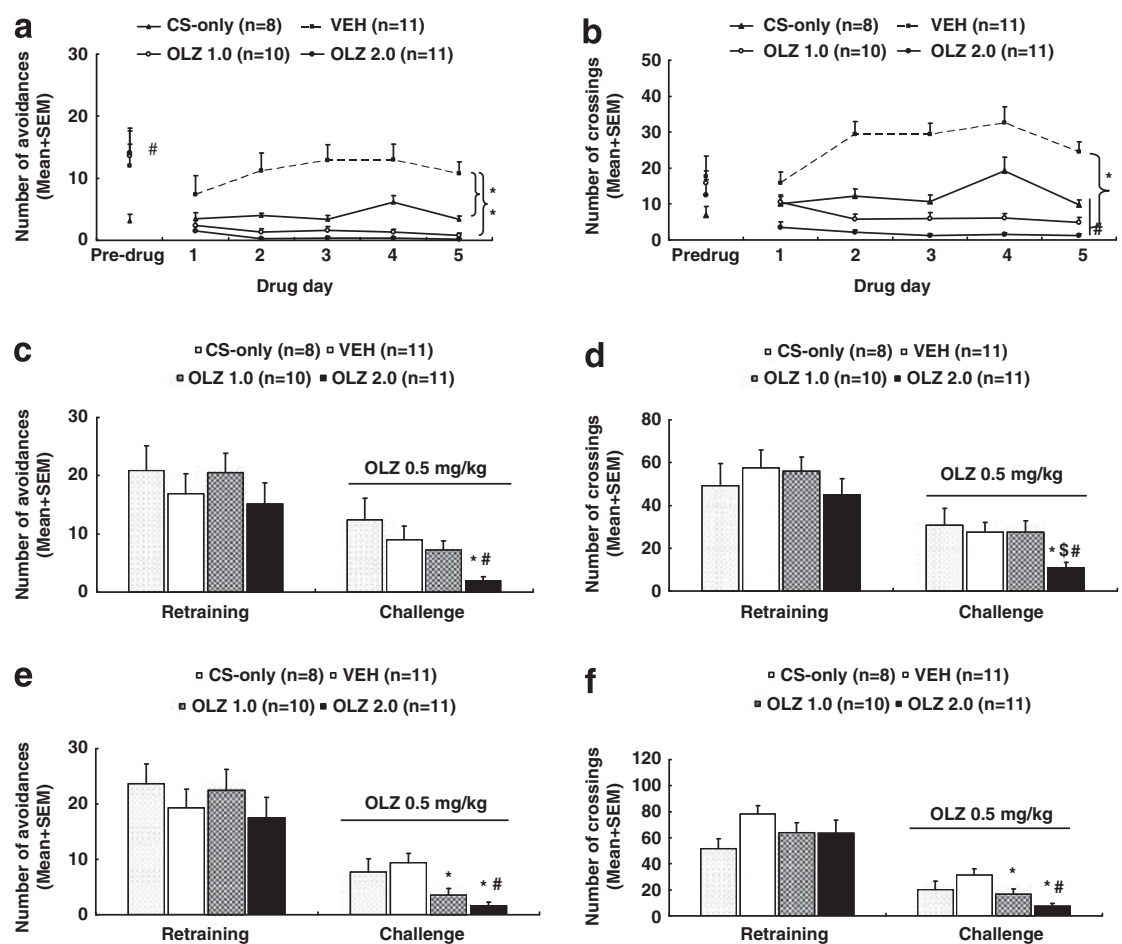

Figure 3 Olanzapine $(O L Z)$ sensitization induced in adolescence and assessed in adulthood. Number of avoidance responses (a) and intertrial crossing (b) made by the rats from the CS-only, OLZ ( $1.0 \mathrm{mg} / \mathrm{kg}), O L Z(2.0 \mathrm{mg} / \mathrm{kg})$, and vehicle $(V E H)$ groups on the last training (predrug) day and throughout the five drug test days are expressed as mean + SEM. The same measures on the seventh retraining day and the first OLZ sensitization test day (approximate postnatal days $(\sim P) 76$ ) are also expressed as mean + SEM and depicted in $c$ and d, respectively. Data from the predrug day and the second OLZ sensitization test day ( $\sim$ P 92) are depicted in e (avoidance) and $f$ (intertrial crossing), respectively. ${ }^{*} p<0.05$ relative to the $V E H$ group; ${ }^{\#} p<0.05$ relative to the CS-only group; ${ }^{\$} p<0.05$ relative to the OLZ 1.0 group.

$22 \mathrm{kHz}$ USV: On the last training day, rats trained in the CAR emitted significantly more $22 \mathrm{kHz}$ USV than the CS-only rats (the average was $1271.56+160.34$ vs $1.88+1.09$, respectively, $t_{31}=-7.918, p<0.001$; Supplementary Table S3). During the drug test days, the two OLZ groups and the CS-only group emitted fewer $22 \mathrm{kHz}$ USV in comparison with the VEH group. Repeated measures ANOVA revealed a main effect of group, $F(3,36)=12.297, p<0.001$; day, $F(4,144)=16.126, p<0.001$, and a significant group $\times$ day interaction, $F(12,144)=9.443, p<0.001$. Post hoc tests revealed that the two OLZ groups were significantly different from the VEH group, all $p<0.001$, but not significantly different from the CS-only group. The CS-only group also differed significantly from the VEH group, $p<0.001$.

Intertrial crossing: No significant group difference was found on the intertrial crossing on the last training day (Figure 3b). During the drug test days, the two OLZ groups and the CS-only group had fewer intertrial crossings in comparison with the VEH group. Repeated measures ANOVA revealed a main effect of group, $F(3,36)=40.108$, $p<0.001$; day, $F(4,144)=5.971, p<0.001$, and a significant group $\times$ day interaction, $F(12,144)=6.334, p<0.001$. Post hoc tests revealed that the two OLZ groups and the CS-only group were significantly different from the VEH group, all $p<0.001$. The two OLZ groups were also significantly different from the CS-only group, $p<0.038$.

Sensitization assessment in adulthood on $P 76$ and 92.

Avoidance response on $P$ 76: Figure $3 c$ shows the number of avoidance responses on the seventh retraining day and the first sensitization test day $(\sim \mathrm{P} 76)$. Before the OLZ challenge, there was no significant group difference. On the challenge day when all rats were injected with OLZ $0.5 \mathrm{mg} / \mathrm{kg}$, the two OLZ groups made fewer avoidance responses than the other two OLZ-naive groups. One-way ANOVA revealed a significant effect of group, $F(3,36)=3.998, p=0.015$. Post hoc LSD tests showed that the OLZ 2.0 group was significantly different from the CSonly group, $p=0.002$ and the $\mathrm{VEH}$ group, $p=0.020$, respectively. However, the OLZ 1.0 group was not significantly different from the other groups.

$22 \mathrm{kHz}$ USV and intertrial crossing on P 76: No significant group difference was detected on the number of $22 \mathrm{kHz}$ USV on the predrug day and on the challenge day (Supplementary Table S3). On the intertrial crossing (Figure 3d), no significant group difference was detected on the predrug day. On the challenge day, one-way ANOVA showed a main effect of group, $F(3,36)=3.274, p=0.032$. Post hoc tests showed that the OLZ 2.0 group was significantly different from the other three groups, $p<0.024$.

Avoidance response on $P$ 92: Figure $3 \mathrm{e}$ shows the number of avoidance responses on the predrug day and the second sensitization test day ( $\sim$ P 92). Before the OLZ challenge, there was no significant group difference. On the challenge day, the two OLZ groups made fewer avoidance responses than the other two groups treated with vehicle during the adolescence period. One-way ANOVA revealed a significant effect of group, $F(3,36)=6.407, p=0.001$. Post hoc tests showed that the OLZ 2.0 group was significantly different from the CS-only group, $p=0.007$ and the VEH group, 

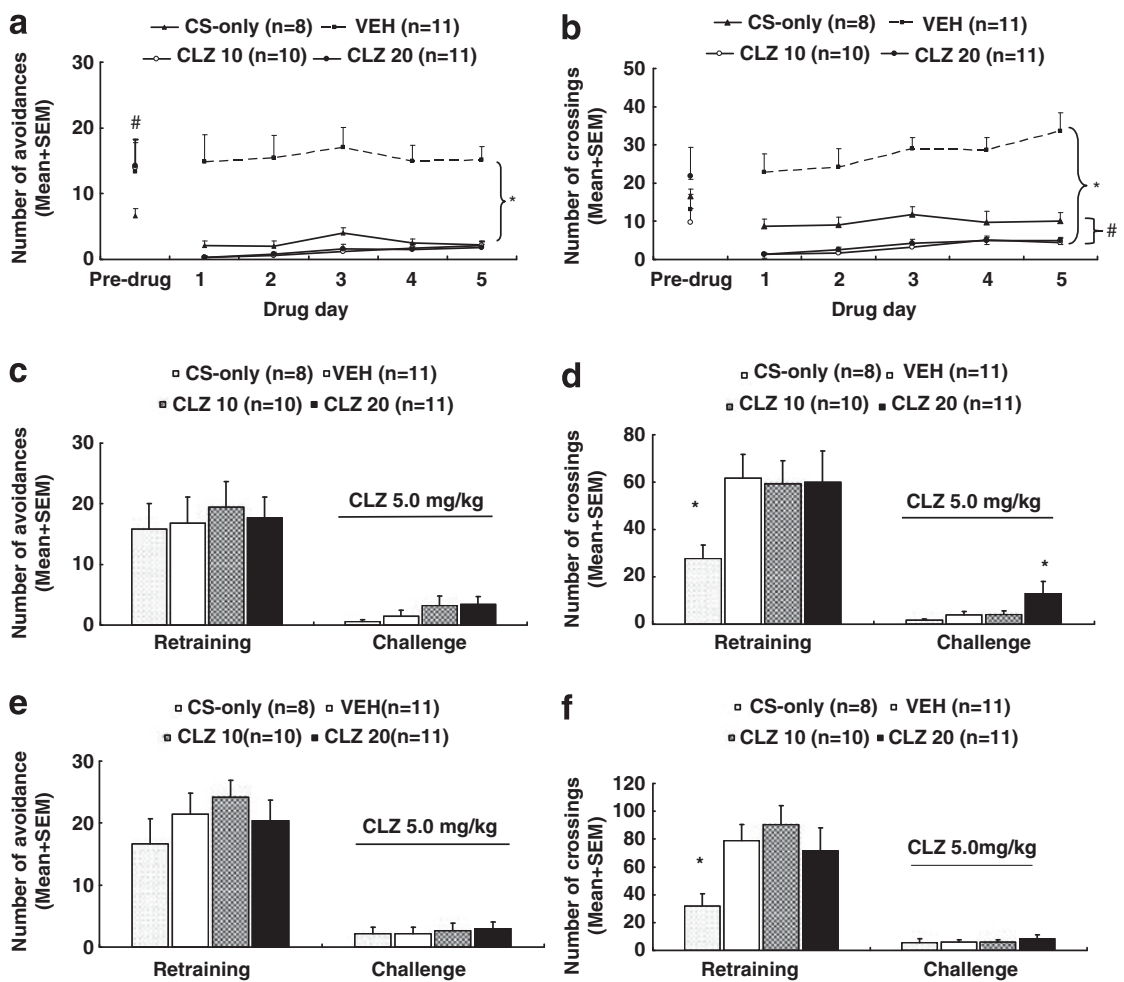

Figure 4 Clozapine (CLZ) tolerance induced in adolescence and assessed in adulthood. Number of avoidance responses (a) and intertrial crossing (b) made by the rats from the CS-only, CLZ (I0.0 mg/kg), CLZ $(20.0 \mathrm{mg} / \mathrm{kg})$, and vehicle (VEH) groups on the last training (predrug) day and throughout the five drug test days are expressed as mean + SEM. The same three measures on the seventh retraining day and the first CLZ tolerance test day (approximate postnatal days $(\sim P) 76$ ) are also expressed as mean + SEM and depicted in c and d, respectively. Data from the predrug day and the second CLZ tolerance test day ( $\sim$ P 92) are depicted in e (avoidance) and $f$ (intertrial crossing), respectively. ${ }^{*} p<0.05$ relative to the VEH group; ${ }^{\#} p<0.05$ relative to the CS-only group.

$p<0.001$, respectively. The OLZ 1.0 group was also significantly different from the VEH group, $p=0.006$, and marginally different from the CS-only group, $p=0.067$.

$22 \mathrm{kHz} U S \mathrm{~V}$ and intertrial crossing on $P$ 92: There was no significant group difference on the $22 \mathrm{kHz}$ USV on the predrug day and on the challenge day (Supplementary Table S3). Similarly, no significant group difference was detected on the intertrial crossing on the predrug day (Figure 3f). On the challenge day, one-way ANOVA showed a main effect of group, $F(3,36)=5.840, p=0.002$. Post hoc tests showed that the OLZ 2.0 group was significantly different from the VEH group, $p<0.001$ and the CS-only group, $p=0.048$. The OLZ 1.0 group was also significantly different from the VEH group, $p=0.019$.

Collectively, the above findings indicate that repeated OLZ treatment in adolescence induced a strong sensitization effect in adulthood that was dose-dependent, longlasting, and behavioral specific, as it was only shown in avoidance response and intertrial crossing, but not in $22 \mathrm{kHz}$ USV. The main difference between the OLZ sensitization assessed during adolescence and the one assessed during adulthood was that it also manifested itself in the intertrial crossing in adulthood.

PPI assessment. PPI data from the 3 time points of testing $(\sim \mathrm{P} 48,67$ and 77$)$ did not reveal any significant group difference (Supplemetary Figure S1A, 1B and 1C). The group $\times$ prepulse level interaction was only significant on $P$
$67, p=0.012$. However, one-way ANOVA failed to find any significant group difference at each prepulse level. These findings suggest that repeated OLZ treatment did not significantly impair the sensorimotor gating ability, a finding consistent with a previous report (Llorente-Berzal et al, 2012).

\section{Experiment 4: CLZ Tolerance Induced in Adolescence and Assessed in Adulthood}

Avoidance response during adolescence: Figure 4a shows the number of avoidance responses made by the rats in the four groups on the last adolescence training day and throughout the five drug test sessions. At the end of the training phase, rats trained in the CAR had a significantly higher level of avoidance responding than the CS-only rats (the average was $13.84+2.36$ vs $6.63+1.15$, respectively, $t_{38}=-2.747$, $p=0.009$ ). During the drug test days, the two CLZ groups and the CS-only group made fewer avoidance responses, whereas the VEH group maintained a high level of avoidance responding. Repeated measures ANOVA revealed a main effect of group, $F(3,36)=23.111, p<0.001$, but no main effect of day nor group $\times$ day interaction. Post hoc LSD tests revealed that the two CLZ groups were significantly different from the VEH group, all $p<0.001$, but not significantly different from the CS-only group. The CS-only group also differed significantly from the VEH group, $p<0.001$. 
$22 \mathrm{kHz} U S \mathrm{~V}$ : On the last training day, rats trained in the CAR emitted significantly more $22 \mathrm{kHz}$ USV than the CSonly rats (the average was $625.38+143.65 v s 1.63+0.50$, respectively, $t_{31}=-4.342, p<0.001$; Supplementary Table S4). During the drug test days, the two CLZ groups and the CS-only group had fewer $22 \mathrm{kHz}$ USV compared with the VEH group. Repeated measures ANOVA revealed a main effect of group, $F(3,36)=5.721, p=0.003$, but no main effect of day nor group $\times$ day interaction. Post hoc tests revealed that the two CLZ groups were significantly different from the VEH group, all $p<0.003$, but not significantly different from the CS-only group. The CS-only group also differed significantly from the VEH group, $p=0.003$.

Intertrial crossing: There was no significant group difference on the intertrial crossing on the last training day. During the drug test days, the two CLZ groups and the CS-only group had fewer intertrial crossings in comparison with the VEH group (Figure $4 \mathrm{~b}$ ). Repeated measures ANOVA revealed a main effect of group, $F(3,36)=42$. $029, p<0.001$; day, $F(4,144)=3.984, p=0.004$, but no significant group $\times$ day interaction. Post hoc tests revealed that the two CLZ groups and the CS-only group were significantly different from the VEH group, all $p<0.001$. The two CLZ groups were also significantly different from the CS-only group, $p<0.027$.

\section{Tolerance assessment in adulthood on P 76 and 92.}

Avoidance response on $P$ 76: Figure $4 \mathrm{c}$ shows the number of avoidance responses on the seventh retraining day and the first tolerance test day $(\sim \mathrm{P} 76)$. Before the CLZ challenge, there was no significant group difference. On the challenge day when all rats were injected with CLZ $5.0 \mathrm{mg} /$ $\mathrm{kg}$, rats from all four groups exhibited a similar low level of avoidance responding. One-way ANOVA did not find a significant main effect of group.

$22 \mathrm{kHz}$ USV and intertrial crossing on P 76: No significant group difference was detected on the $22 \mathrm{kHz}$ USV, on the predrug day and on the challenge day (Supplementary Table S4). Similarly, on the intertrial crossing (Figure 4d) there was no significant group difference on the predrug day, although a post-hoc two group comparison found that the CS-only group had significantly fewer crossings than the vehicle group, $p=0.035$. On the challenge day, one-way ANOVA showed a main effect of group, $F(3,36)=2.893$, $p=0.049$. Post hoc tests showed that the CLZ 20 group had significantly higher crossings than the other three groups, $p<0.039$.

Avoidance response on $P$ 92: Figure $4 \mathrm{e}$ shows the number of avoidance responses, on the predrug day and the second tolerance test day ( $\sim$ P 92). Once again, no significant group difference was detected on both days.

$22 \mathrm{kHz}$ USV and intertrial crossing on $P$ 92: No significant group difference on the $22 \mathrm{kHz}$ USV was detected on the predrug day and on the challenge day (Supplementary Table S4). On the intertrial crossing (Figure 4f), there was a significant group difference on the predrug day, $F(3,36)=3.151, p=0.037$, with the CS-only group made fewer crossings than the other three groups, $p<0.049$. On the challenge day, the group difference was not significant.
Collectively, the above findings indicate that repeated CLZ treatment during adolescence did not induce a robust tolerance effect in avoidance response during adulthood at both time points. The CLZ tolerance effect was only found in the intertrial crossing on $\sim \mathrm{P} 76$. As the three measures (avoidance, $22 \mathrm{kHz}$ USV, and intertrial crossing) in the CAR task may represent three putative behavioral effects of CLZ (ie, antipsychotic, anxiolytic, and motor impairment/ sedative effect), results from this experiment suggest that adolescent CLZ treatment induced a tolerance to its motor impairment/sedative effect, whereas its antipsychotic and anxiolytic effects did not undergo tolerance.

PPI assessment. PPI data from the 3 time points of testing $(\sim \mathrm{P} 48,67$ and 77$)$ did not reveal any significant group difference (Supplementary Figure S2A, 2B and 2C). The group $\times$ prepulse level interactions were also not significant. These findings suggest that repeated CLZ treatment did not significantly impair the sensorimotor gating ability.

\section{DISCUSSION}

Although onset of schizophrenia typically occurs in late adolescence, most preclinical work on the behavioral effects and mechanisms of action of antipsychotic drugs has been often conducted on adult animals. The present study asked two critical questions as follows: (1) Can OLZ sensitization and CLZ tolerance be induced in adolescent rats? (2) Can OLZ sensitization and CLZ tolerance induced in adolescence persist into adulthood? The answer to both questions is yes. We demonstrated that OLZ sensitization and CLZ tolerance could be induced in adolescent rats using the same procedure (ie, an induction phase followed by a challenge test) as employed in adult rats (Li et al, 2004; Li et al, 2007; Li et al, 2009a; Li et al, 2009b; Li et al, 2010; Mead and Li, 2010; Li et al, 2012; Zhang and Li, 2012). They mainly manifested in the avoidance response (a behavioral measure of antipsychotic activity) and/or intertrial crossing (a behavioral measure of motor function/sedation), but not in the $22 \mathrm{kHz}$ USV (an index of anxiolytic property), suggesting that they are behaviorally specific (Stewart and Badiani, 1993). Furthermore, the magnitude of both effects depended on the initial treatment doses of OLZ and CLZ, and the persistence of such effects also depended on the specific drugs (ie, CLZ vs OLZ). In this sense, these longterm effects may reflect the intrinsic pharmacological properties of OLZ and CLZ.

The most remarkable findings of the present study were the demonstrations of the long-lasting OLZ sensitization and the transient CLZ tolerance across the adolescence and adulthood developmental periods in the CAR model. To the best of our knowledge, this is the first demonstration of such effects in a valid behavioral test of antipsychotic activity. The majority of preclinical research on adolescence antipsychotic treatment has often focused on two issues. One is the age difference in psychopharmacological responsiveness and brain responses to antipsychotics between adolescent animals and adult ones (Spear and Brake, 1983; Moran-Gates et al, 2006; Wiley, 2008; Choi et al, 2010). The common approach is to compare animals in different age groups on their behavioral responses 
(eg, locomotor activity, catalepsy; Wiley and Evans, 2008) and brain responses (eg, dopamine and 5-HT receptors; Moran-Gates et al, 2006; Choi et al, 2010) to various antipsychotic treatments, without tracking changes across the different development stages. The second issue of interest is the long-term behavioral and brain consequences of antipsychotic treatment in adolescence (Llorente-Berzal et al, 2012). One focal area is the potential preventive or treatment effects of adolescence antipsychotic exposure on behavioral and brain abnormalities in animal models of schizophrenia (Piontkewitz et al, 2009; Piontkewitz et al, 2011). The present study differed from those studies in that it focused on how antipsychotic treatment during adolescence alters antipsychotic response in adolescence and beyond (eg, adulthood). Indeed, very little prior research has been done on this topic. We could only find one study that showed a haloperidol-induced sensitization effect on catalepsy (Spear et al, 1980). The lack of research on this topic is not surprising given that antipsychotic sensitization and tolerance are relatively newly recognized phenomena even in adult animals (Li et al, 2010; Zhang and Li, 2012).

OLZ and other antipsychotic drugs, such as haloperidol and risperidone, often induce a sensitization effect in a variety of animal behaviors. Besides the CAR test, it has been reported in a catalepsy test (Lanis and Schmidt, 2001; Amtage and Schmidt, 2003; Klein and Schmidt, 2003), a PCP-induced hyperlocomotion test (Sun et al, 2009; Zhang and Li, 2012), a PPI of acoustic startle procedure (Li et al, 2011), an operant responding procedure (Varvel et al, 2002), as well as in the metabolic effect (Boyda et al, 2012). In contrast, CLZ often induces a tolerance effect ( $\mathrm{Li}$ et al, 2010). CLZ-induced tolerance has also been observed in a drug discrimination task (Goudie et al, 2007a; Goudie et al, 2007b) and in a PCP-induced hyperlocomotion (unpublished observations). In the present study, we noted that CLZ tolerance seems to be weaker than OLZ sensitization in terms of its persistence. It only manifested in the intertrial crossing on $\sim \mathrm{P} 76$ but not on $\sim \mathrm{P} 92$, whereas OLZ sensitization manifested in both avoidance response and intertrial crossing, and at both time points. What account for their differences is not entirely clear. On the basis of our previous work on the neuroceptor mechanisms of OLZ sensitization and CLZ tolerance in adult rats ( $\mathrm{Li}$ et al, 2010; Li et al, 2012), we speculate that their differential (even opposing) actions on dopamine $\mathrm{D}_{2 / 3}$ receptors may be one of the factors, as we show that pretreatment of quinpirole, a selective $D_{2} / D_{3}$ dopaminergic receptor agonist, attenuated OLZ sensitization but enhanced CLZ tolerance on avoidance response. Future work should investigate the role of dopamine $\mathrm{D}_{2 / 3}$ receptors in the mediation of OLZ sensitization and CLZ tolerance in adolescence.

In the present study as well as our previous ones (Sun et al, 2009; Li et al, 2010), we have observed no differences in behavioral responsiveness to OLZ and CLZ in the induction phase (ie, the repeated drug treatment period), but differences in the expression phase (ie, the challenge test). For example, during the drug treatment period in both the CAR and the PCP-induced hyperlocomotion model (ie, the induction phase), repeated OLZ and CLZ treatment persistently inhibited avoidance response and PCP-induced hyperlocomotion. OLZ and CLZ did not differ from each other (Sun et al, 2009; Li et al, 2010). Only in the later challenge test (ie, the expression phase) did we observe the pattern differences between OLZ and CLZ. Other psychotropic drugs have also shown differential effects in different phases (Stewart and Badiani, 1993). These findings suggest that the expression of OLZ sensitization or CLZ tolerance does not necessarily require the manifestation of such an effect during the induction phase. As there is evidence suggesting that the induction and expression of behavioral sensitization involve independent neural systems (Cador et al, 1995), it is likely that the induction and expression of OLZ sensitization and CLZ tolerance may also involve different processes and mechanisms that affect ongoing behaviors differentially.

In our previous rat CAR studies (Mead et al, 2008; Sun et al, 2010), we have shown that OLZ and CLZ as atypical antipsychotics also possess an intrinsic anxiolytic property as revealed by their ability to decrease various behavioral and physiological measures of anxiety/fear (eg, stressinduced hyperthermia, $22 \mathrm{kHz}$ USV, startle reactivity, defecation, and urination), in addition to their antipsychotic property as indexed by their anti-avoidance effect. These two properties seem dissociable and might be mediated by their different molecular actions. For example, OLZinduced elevations in allopregnanolone is shown to mediate its anxiolytic effect (Frye and Seliga, 2003), whereas its action on $\mathrm{D}_{2}$ receptors is responsible for its antipsychotic effect (Kapur et al, 1998). Interestingly, the present study added another piece of evidence for the dissociated anxiolytic and antipsychotic actions of OLZ and CLZ, as both OLZ-induced sensitization and CLZ-induced tolerance were selective to their putative antipsychotic effect (eg, antiavoidance) and not to their anxiolytic effect (eg, a decreasing effect on $22 \mathrm{kHz}$ USV). Different behavioral effects of a drug undergo different time courses of change with repeated drug administration are certainly not new (Stewart and Badiani, 1993).

Adolescence is a period in which the brain undergoes dramatic transitions and re-organization (Brenhouse and Andersen, 2011). For example, adolescents tend to overexpress various neuroreceptors (eg, dopaminergic, adrenergic, serotonergic) followed by pruning to adult levels (an inverted U-shape curve of development). Both dopamine receptors (eg, $D_{1}, D_{2}$ ) and serotonergic receptors (eg, 5$\mathrm{HT}_{1 \mathrm{~A}}, 5-\mathrm{HT}_{2 \mathrm{~A}}$ ) that are implicated in the mechanisms of action of antipsychotic drugs are reported to be expressed at higher levels in various brain areas (eg, cerebral cortex, hippocampus, dorsal and ventral striatum, and septum) during adolescence than in adulthood (Lidow et al, 1991; Teicher et al, 1995; Tarazi et al, 1998; Andersen et al, 2000), and antipsychotic exposure alters these neuroreceptors in unique ways not seen in adult animals (Moran-Gates et al, 2006; Choi et al, 2009; Choi et al, 2010). For instance, Moran-Gates et al (2006) found that repeated administration of OLZ (5 mg/kg, once daily) and CLZ (20 mg/kg, twice daily) from $\mathrm{P} 22$ to $\mathrm{P} 42$, all decreased $\mathrm{D}_{1}$ receptors in dorsolateral frontal and medial prefrontal cortex of adolescent, but not adult rats. In contrast, both drugs increased $\mathrm{D}_{2}$ receptors in the medial prefrontal cortex of adult, but not adolescent rats (Moran-Gates et al, 2006). OLZ, but not CLZ, also increased $\mathrm{D}_{2}$ receptor levels in hippocampus, and $\mathrm{D}_{4}$ levels in nucleus accumbens and caudate-putamen in both juvenile and adult rats. The 
finding that OLZ sensitization and CLZ tolerance had survived the adolescent period indicates that certain druginduced brain changes may be relatively permanent. One important line of research is to delineate how antipsychotics induce brain changes and identify where these changes take place.

As antipsychotic drugs are being increasingly used in children and adolescents in the past two decades (Olfson et al, 2006), findings from this study are important for the understanding of the impacts of adolescence antipsychotic treatment on the brain and behavioral developments and associated behavioral and neurobiological mechanisms. Our findings suggest that antipsychotic exposure during adolescence could alter the trajectory of the brain and behavioral development of pediatric patients, which in turn may change their later response to drug treatment as adults. Currently, antipsychotic drugs are often used in the short term to calm disturbed children with irritability associated with autism, tic disorders, obsessive-compulsive disorder, posttraumatic stress disorder, and aggression (Correll et al, 2011). The long-term consequences of such exposures on psychological functions and other aspects of brain maturation at various ages have not been systematically investigated and are less well understood. The present study points out that even 5 days of drug exposure could induce a longlasting effect that persists into adulthood. Thus, for the clinical practice, such a long-term consequence of adolescence antipsychotic treatment needs to be better understood and monitored, as many pediatric patients need medications after they become adults.

\section{ACKNOWLEDGEMENTS}

This study was funded in part by the NIMH grant (R01MH085635) to Professor Ming Li.

\section{DISCLOSURE}

The authors declare no conflict of interest.

\section{REFERENCES}

Amtage J, Schmidt WJ (2003). Context-dependent catalepsy intensification is due to classical conditioning and sensitization. Behav Pharmacol 14: 563-567.

Andersen SL, Thompson AT, Rutstein M, Hostetter JC, Teicher MH (2000). Dopamine receptor pruning in prefrontal cortex during the periadolescent period in rats. Synapse 37: 167-169.

Barnes DE, Robinson B, Csernansky JG, Bellows EP (1990). Sensitization versus tolerance to haloperidol-induced catalepsy: multiple determinants. Pharmacol Biochem Behav 36: 883-887.

Boyda HN, Procyshyn RM, Tse L, Wong D, Pang CC, Honer WG et al (2012). Intermittent treatment with olanzapine causes sensitization of the metabolic side-effects in rats. Neuropharmacology 62: 1391-1400.

Brenhouse HC, Andersen SL (2011). Developmental trajectories during adolescence in males and females: a cross-species understanding of underlying brain changes. Neurosci Biobehav Rev 35: 1687-1703.

Cador M, Bjijou Y, Stinus L (1995). Evidence of a complete independence of the neurobiological substrates for the induction and expression of behavioral sensitization to amphetamine. Neuroscience 65: 385-395.
Choi YK, Gardner MP, Tarazi FI (2009). Effects of risperidone on glutamate receptor subtypes in developing rat brain. Eur Neuropsychopharmacol 19: 77-84.

Choi YK, Moran-Gates T, Gardner MP, Tarazi FI (2010). Effects of repeated risperidone exposure on serotonin receptor subtypes in developing rats. Eur Neuropsychopharmacol 20: 187-194.

Correll CU, Kratochvil CJ, March JS (2011). Developments in pediatric psychopharmacology: focus on stimulants, antidepressants, and antipsychotics. J Clin Psychiatry 72: 655-670.

Culm KE, Hammer RP Jr. (2004). Recovery of sensorimotor gating without $G$ protein adaptation after repeated D2-like dopamine receptor agonist treatment in rats. J Pharmacol Exp Ther 308: 487-494.

Emmett-Oglesby MW, Goudie AJ (1989). Psychoactive Drugs: Tolerance and Sensitization. Humana Press: Clifton, NJ.

Frye CA, Seliga AM (2003). Olanzapine's effects to reduce fear and anxiety and enhance social interactions coincide with increased progestin concentrations of ovariectomized rats. Psychoneuroendocrinology 28: 657-673.

Geyer MA, Braff DL (1987). Startle habituation and sensorimotor gating in schizophrenia and related animal models. Schizophr Bull 13: 643-668.

Gleason SD, Shannon HE (1997). Blockade of phencyclidineinduced hyperlocomotion by olanzapine, clozapine and serotonin receptor subtype selective antagonists in mice. Psychopharmacology (Berl) 129: 79-84.

Goudie AJ, Cole JC, Sumnall HR (2007a). Olanzapine and JL13 induce cross-tolerance to the clozapine discriminative stimulus in rats. Behav Pharmacol 18: 9-17.

Goudie AJ, Cooper GD, Cole JC, Sumnall HR (2007b). Cyproheptadine resembles clozapine in vivo following both acute and chronic administration in rats. J Psychopharmacol 21: 179-190.

Kapur S, VanderSpek SC, Brownlee BA, Nobrega JN (2003). Antipsychotic dosing in preclinical models is often unrepresentative of the clinical condition: a suggested solution based on in vivo occupancy. J Pharmacol Exp Ther 305: 625-631.

Kapur S, Zipursky RB, Remington G (1999). Clinical and theoretical implications of 5-HT2 and D2 receptor occupancy of clozapine, risperidone, and olanzapine in schizophrenia. Am J Psychiatry 156: 286-293.

Kapur S, Zipursky RB, Remington G, Jones C, DaSilva J, Wilson AA et al (1998). 5-HT2 and D2 receptor occupancy of olanzapine in schizophrenia: a PET investigation. Am J Psychiatry 155: 921-928.

Klein A, Schmidt WJ (2003). Catalepsy intensifies contextdependently irrespective of whether it is induced by intermittent or chronic dopamine deficiency. Behav Pharmacol 14: 49-53.

Lanis A, Schmidt WJ (2001). NMDA receptor antagonists do not block the development of sensitization of catalepsy, but make its expression state-dependent. Behav Pharmacol 12: 143-149.

Li M, Fletcher PJ, Kapur S (2007). Time course of the antipsychotic effect and the underlying behavioral mechanisms. Neuropsychopharmacology 32: 263-272.

Li M, He E, Volf N (2011). Time course of the attenuation effect of repeated antipsychotic treatment on prepulse inhibition disruption induced by repeated phencyclidine treatment. Pharmacol Biochem Behav 98: 559-569.

Li M, He W, Mead A (2009a). An investigation of the behavioral mechanisms of antipsychotic action using a drug-drug conditioning paradigm. Behav Pharmacol 20: 184-194.

Li M, He W, Mead A (2009b). Olanzapine and risperidone disrupt conditioned avoidance responding in phencyclidine-pretreated or amphetamine-pretreated rats by selectively weakening motivational salience of conditioned stimulus. Behav Pharmacol 20: 84-98.

Li M, Parkes J, Fletcher PJ, Kapur S (2004). Evaluation of the motor initiation hypothesis of APD-induced conditioned avoidance decreases. Pharmacol Biochem Behav 78: 811-819. 
Li M, Sun T, Mead A (2012). Clozapine, but not olanzapine, disrupts conditioned avoidance response in rats by antagonizing 5-HT(2A/2C) receptors. J Neural Transm 119: 497-505.

Li M, Sun T, Zhang C, Hu G (2010). Distinct neural mechanisms underlying acute and repeated administration of antipsychotic drugs in rat avoidance conditioning. Psychopharmacology (Berl) 212: 45-57.

Lidow MS, Goldman-Rakic PS, Rakic P (1991). Synchronized overproduction of neurotransmitter receptors in diverse regions of the primate cerebral cortex. Proc Natl Acad Sci USA 88: 10218-10221.

Llorente-Berzal A, Mela V, Borcel E, Valero M, Lopez-Gallardo M, Viveros MP et al (2012). Neurobehavioral and metabolic longterm consequences of neonatal maternal deprivation stress and adolescent olanzapine treatment in male and female rats. Neuropharmacology 62: 1332-1341.

Mead A, Li M (2010). Avoidance-suppressing effect of antipsychotic drugs is progressively potentiated after repeated administration: an interoceptive drug state mechanism. J Psychopharmacol 24: 1045-1053.

Mead A, Li M, Kapur S (2008). Clozapine and olanzapine exhibit an intrinsic anxiolytic property in two conditioned fear paradigms: contrast with haloperidol and chlordiazepoxide. Pharmacol Biochem Behav 90: 551-562.

Meyer U, Spoerri E, Yee BK, Schwarz MJ, Feldon J (2010). Evaluating early preventive antipsychotic and antidepressant drug treatment in an infection-based neurodevelopmental mouse model of schizophrenia. Schizophr Bull 36: 607-623.

Moran-Gates T, Gan L, Park YS, Zhang K, Baldessarini RJ, Tarazi FI (2006). Repeated antipsychotic drug exposure in developing rats: dopamine receptor effects. Synapse 59: 92-100.

Natesan S, Reckless GE, Nobrega JN, Fletcher PJ, Kapur S (2005). Dissociation between in vivo occupancy and functional antagonism of dopamine $\mathrm{D}(2)$ receptors: comparing aripiprazole to other antipsychotics in animal models. Neuropsychopharmacology 31: 1854-1863.

Olfson M, Blanco C, Liu L, Moreno C, Laje G (2006). National trends in the outpatient treatment of children and adolescents with antipsychotic drugs. Arch Gen Psychiatry 63: 679-685.

Piontkewitz Y, Arad M, Weiner I (2011). Risperidone administered during asymptomatic period of adolescence prevents the emergence of brain structural pathology and behavioral abnormalities in an animal model of schizophrenia. Schizophr Bull 37: 1257-1269.

Piontkewitz Y, Assaf Y, Weiner I (2009). Clozapine administration in adolescence prevents postpubertal emergence of brain structural pathology in an animal model of schizophrenia. Biol Psychiatry 66: 1038-1046.

Remington G, Kapur S (2010). Antipsychotic dosing: how much but also how often? Schizophr Bull 36: 900-903.

Robinson TE, Browman KE, Crombag HS, Badiani A (1998). Modulation of the induction or expression of psychostimulant sensitization by the circumstances surrounding drug administration. Neurosci Biobehav Rev 22: 347-354.
Sparkman NL, Li M (2012). Drug-drug conditioning between citalopram and haloperidol or olanzapine in a conditioned avoidance response model: implications for polypharmacy in schizophrenia. Behav Pharmacol 23: 658-668.

Spear LP, Brake SC (1983). Periadolescence: age-dependent behavior and psychopharmacological responsivity in rats. Dev Psychobiol 16: 83-109.

Spear LP, Shalaby IA, Brick J (1980). Chronic administration of haloperidol during development: behavioral and psychopharmacological effects. Psychopharmacology (Berl) 70: 47-58.

Stewart J, Badiani A (1993). Tolerance and sensitization to the behavioral effects of drugs. Behav Pharmacol 4: 289-312.

Sun T, He W, Hu G, Li M (2010). Anxiolytic-like property of risperidone and olanzapine as examined in multiple measures of fear in rats. Pharmacol Biochem Behav 95: 298-307.

Sun T, Hu G, Li M (2009). Repeated antipsychotic treatment progressively potentiates inhibition on phencyclidine-induced hyperlocomotion, but attenuates inhibition on amphetamineinduced hyperlocomotion: relevance to animal models of antipsychotic drugs. Eur J Pharmacol 602: 334-342.

Swalve N, Li M (2012). Parametric studies of antipsychoticinduced sensitization in the conditioned avoidance response model: roles of number of drug exposure, drug dose, and testretest interval. Behav Pharmacol 23: 380-391.

Swerdlow NR, Weber M, Qu Y, Light GA, Braff DL (2008). Realistic expectations of prepulse inhibition in translational models for schizophrenia research. Psychopharmacology (Berl) 199: 331-388.

Tarazi FI, Tomasini EC, Baldessarini RJ (1998). Postnatal development of dopamine and serotonin transporters in rat caudate-putamen and nucleus accumbens septi. Neurosci Lett 254: $21-24$

Teicher MH, Andersen SL, Hostetter JC Jr. (1995). Evidence for dopamine receptor pruning between adolescence and adulthood in striatum but not nucleus accumbens. Brain Res Dev Brain Res 89: 167-172.

Varvel SA, Vann RE, Wise LE, Philibin SD, Porter JH (2002). Effects of antipsychotic drugs on operant responding after acute and repeated administration. Psychopharmacology (Berl) 160: 182-191.

Wadenberg ML (2010). Conditioned avoidance response in the development of new antipsychotics. Curr Pharm Des 16: 358-370.

Wiley JL (2008). Antipsychotic-induced suppression of locomotion in juvenile, adolescent and adult rats. Eur J Pharmacol 578: 216-221.

Wiley JL, Evans RL (2008). Evaluation of age and sex differences in locomotion and catalepsy during repeated administration of haloperidol and clozapine in adolescent and adult rats. Pharmacol Res 58: 240-246.

Zhang C, Li M (2012). Contextual and behavioral control of antipsychotic sensitization induced by haloperidol and olanzapine. Behav Pharmacol 23: 66-79.

Zhao C, Sun T, Li M (2012). Neural basis of the potentiated inhibition of repeated haloperidol and clozapine treatment on the phencyclidine-induced hyperlocomotion. Prog Neuropsychopharmacol Biol Psychiatry 38: 175-182.

Supplementary Information accompanies the paper on the Neuropsychopharmacology website (http://www.nature.com/npp) 